\title{
O ESTADO DE COISAS INCONSTITUCIONAL: Apontamentos Comparativos Sobre a Judicialização das Políticas Penitenciárias Brasileira e Colombiana
}

\author{
http://dx.doi.org/10.21527/2176-6622.2020.54.273-287
}

Recebido em: 8/3/2020

Modificações solicitadas em: 26/6/2020

Aceito em: 28/7/2020

Edith Maria Barbosa Ramos

Pós-Doutorado em Direito Sanitário pela Fundação Oswaldo Cruz - Fiocruz/Brasília/DF. Doutorado em Políticas Públicas pela Universidade Federal do Maranhão. Mestrado em Direito pela Universidade Federal de Minas Gerais. Graduação em Direito pela Universidade Federal do Maranhão. Professora do Departamento de Direito e do Mestrado em Direito e Instituições do Sistema de Justiça da Universidade Federal do Maranhão. Coordenadora do Núcleo de Estudos em Direito Sanitário (Nedisa/Ufma). Professora, pesquisadora e coordenadora do Mestrado Profissional em Direito da Universidade do Ceuma. Membro Convidado da Rede Ibero-Americana de Direito Sanitário. Presidente da Comissão de Bioética e Biodireito do Conselho Seccional da OAB/MA. http://lattes.cnpq.br/7085054421011701. https://orcid. org/0000-0001-6064-1879. edithramosadv@yahoo.com.br

\section{Pedro Trovão do Rosário}

Doutorado em Direito (Direito Constitucional e Político). Orientador de Teses de Doutoramento e de Dissertações de Mestrado, tendo participado como membro (presidente, arguente ou vogal) em diversos júris de Mestrado e de Doutoramento em Direito em Universidades Europeias. Diretor do Departamento de Direito da Universidade Autónoma de Lisboa e vice-presidente da Fundación Universitária Internacional, com sede em Madrid. Doutor Honoris Causa pela Universidade Latino Americana e do Caribe (Ulac), com sede em Caracas (Venezuela). Membro Internacional da Comissão de Direito à Educação na Seccional da Ordem dos Advogados do Brasil do Estado do Rio de Janeiro e membro Emérito da Comissão de Estudos de Direito Comparado da Ordem dos Advogados do Brasil (Rio de Janeiro - 57a subsecção). Investigador registrado na Fundação para a Ciência e a Tecnologia (FCT). http:// lattes.cnpq.br/9012033088047689. https://orcid.org/0000-0002-2891-4053. edithramosadv@yahoo.com.br

Adriana Sousa Lima

Mestranda no Programa de Pós-Graduação em Direito e Instituições do Sistema de Justiça (Direito, Ufma). Graduação em Direito pela Universidade Federal do Maranhão. http://lattes.cnpq.br/7462585095090426e. https:// orcid.org/0000-0003-4076-5473. adrisoulima@gmail.com

\section{RESUMO}

O presente artigo analisou o Estado de Coisas Inconstitucional (ECI) a partir da teorização da judicialização da política e do ativismo judicial, com enfoque no cotejo da aplicação do $\mathrm{ECl}$, em matéria prisional, pelos sistemas judiciários brasileiro e colombiano. A investigação pautou-se no método dedutivo, com utilização de pesquisa teórica (bibliográfica) e jurisprudencial comparativa (Sentencia T-153/98, Sentencia T-388/13 e Sentencia T-762/15 da Corte Constitucional da Colômbia e ADPF 347/DF-MC do Supremo Tribunal Federal), com ênfase na estratégia da análise de conteúdo desses julgados. Constatou-se que o ECl é uma forma de ativismo judicial estrutural, cujo pioneirismo da Corte colombiana constitui-se marco judiciário importante para o diálogo transconstitucional, visando à proteção de direitos fundamentais.

Palavras-chave: Judicialização da política. Ativismo judicial. Estado de Coisas Inconstitucional. Sistema penitenciário. Direito Constitucional Comparado.

THE STATE OF UNCONSTITUTIONAL THINGS:

COMPARATIVE NOTES ON THE JUDICIALIZATION OF BRAZILIAN AND COLOMBIAN PRISON POLICIES

\section{ABSTRACT}

This article analyzed the Unconstitutional State of Things (ECI), based on the theorization of the judicialization of politics and judicial activism, focusing on the comparison of the application of the $\mathrm{ECl}$, in prison matters, by the Brazilian and Colombian judicial systems. The investigation focused on the deductive method, using theoretical (bibliographic) and comparative jurisprudential research (Sentencia T-153/98, Sentencia T-388/13 and Sentencia T-762/15 of the Constitutional Court of Colombia and ADPF 347/DF-MC of the Supreme Court), with emphasis on the strategy of content analysis of these judges. It was found that the $\mathrm{ECl}$ is a form of structural judicial activism, whose pioneering role of the Colombian Court is an important judicial framework for the transconstitutional dialogue aimed at the protection of fundamental rights.

Keywords: Judicialization of politics. Judicial activism. Unconstitutional State of Things. Penitentiary system. Comparative Constitutional Law.

\section{SUMÁRIO}

1 Introdução. 2 Judicialização da política e ativismo judicial. 2.1 Considerações Preliminares. 2.2 Perspectiva histórica. 3 Estado de coisas inconstitucional. 3.1 ECl e Sistema Prisional: Colômbia e Brasil em perspectiva. 3.1.1 A experiência colombiana. 3.1.2 A experiência brasileira. 4 Considerações finais. 5. Referências. 


\section{Direito自

\section{INTRODUÇÃO}

O objeto central do presente estudo, o chamado Estado de Coisas Inconstitucional (ECI), já causa alvoroço e curiosidade apenas pela sua designação. Nessa perspectiva, suas características essenciais, atreladas à violação coletiva e generalizada de direitos fundamentais e às falhas estruturais decorrentes da omissão de poderes estatais, são questões que já denotam a grandiosidade e a complexidade desse instituto jurídico. Não fosse o bastante, a delimitação temática incidirá na aplicação do $\mathrm{ECl}$ em matéria prisional, outra questão essencialmente delicada e grandiosa.

Assim, objetivou o presente artigo analisar a aplicação do Estado de Coisas Inconstitucional, instituto de origem colombiana, com recorte temático incidente no sistema prisional, e metodologia jurisprudencial comparativa a partir dos julgados da Corte Constitucional da Colômbia (Sentencia T-153/98, Sentencia T-388/13 e Sentencia T-762/15) e do Supremo Tribunal Federal (ADPF 347/DF-MC) proferidos sobre esse objeto específico.

Em razão disso, na presente investigação foram analisados documentos oficiais e textos normativos expedidos por organismos nacionais e internacionais que tratam da temática da judicialização da política. $O$ conjunto de documentos e textos normativos coletados contemplou tratados, constituições, declarações, legislações e normas infralegais. Foram, assim, considerados válidos os documentos e textos normativos que permitiram o levantamento de informações no campo das dimensões indicadas na configuração do objeto pesquisado.

Procedeu-se uma análise histórica e conceitual da ideia de Estado de Coisas Inconstitucional e da construção da concepção de ativismo judicial na Colômbia e no Brasil, objetivando compreender os determinantes que propiciaram sua constituição bem como a atualização do seu processo de configuração. Este texto concentra-se, portanto, em uma oportunidade, do ponto de vista científico, para aquele que pretende discutir a temática do estado de coisas inconstitucional no interior dos sistemas constitucionais colombiano e brasileiro. Tal oportunidade justificou o esforço científico aqui materializado no percurso metodológico necessário para pôr em questão o seguinte pressuposto: sem a efetiva concretização dos direitos fundamentais e sem a superação do elevado grau de desigualdades na consecução do direito, consagrados constitucionalmente, a confecção da Norma Fundamental para um estado democrático de direito representa somente retórica, apenas uma folha de papel.

A presente pesquisa utilizou o método dedutivo, com a apropriação histórica de conceitos como judicialização da política, ativismo judicial e estado de coisas inconstitucional. Para o levantamento de informações, os principais procedimentos de coleta de dados foram bibliográficos e documentais (MARCONI; LAKATOS, 2007).

Foram selecionados livros, artigos e documentos normativos, tendo como descritor de buscas os termos: Judicialização da política; Ativismo judicial; Estado de Coisas Inconstitucional; Sistema penitenciário; Direito Constitucional Comparado. Revisaram-se artigos publicados em revistas científicas, estratificadas no sistema Qualis brasileiro, bem como artigos constante na base de dados Bireme, por meio dos serviços da Medline, Scielo e Lilacs. Destaque-se que se procurou superar posturas metodológicas rígidas, demarcando a análise em diversas variáveis contextuais, quais sejam, jurisdicional, econômica e política, a fim de que se evitasse considerações maniqueístas e sem objetivação científica e se conseguisse empreender uma investigação socialmente situada.

Um estudo que versa sobre a atuação de Cortes Constitucionais exigiu, necessariamente, uma abordagem sobre judicialização da política e ativismo judicial, feitas no segundo capítulo, visando a, essencialmente, deslindar tais expressões que tanto geram dúvidas e agitações.

No item 2, Judicialização da Política e Ativismo Judicial, ainda sob o viés da judicialização da política e do ativismo judicial, realizou-se um percurso histórico desses subtemas, a fim de fincar uma sólida base teórica rumo à práxis da jurisdição constitucional extrema do $\mathrm{ECl}$.

O item 3, apresentado na sequência, trouxe a abordagem do tema central do presente artigo: o Estado de Coisas Inconstitucional, desde a sua origem, abordando conceito e características principais. Em seguida, foram esmiuçadas as experiências colombiana e brasileira, com realce para as razões de decidir dos julgados da CCC (Sentencia T-153/98, Sentencia T-388/13 e Sentencia T-762/15) e do STF (ADPF 347/DF-MC), uma vez que denotam a riqueza técnica de detalhes da aplicação prática do instituto do ECl pelas cortes supremas da Colômbia e do Brasil. 
Por fim, ressalta-se a importância do presente estudo sobretudo para o ordenamento jurídico pátrio, posto que o caso brasileiro da aplicação do $\mathrm{ECl}$ foi decidido apenas em sede de medida cautelar.

\section{JUDICIALIZAÇÃO DA POLÍTICA E ATIVISMO JUDICIAL}

\subsection{Considerações Preliminares}

O presente estudo tem como eixo central a análise do Estado de Coisas Inconstitucional (ECI). Para alcançar tal desiderato, elege-se como percurso teórico inicial e essencial ao deslinde do tema, a abordagem da judicialização da política e do ativismo judicial.

Nesse compasso, surge como premissa básica uma análise, a priori semântica, que engloba a compreensão das expressões "judicialização da política" e "ativismo judicial". Uma compreensão consubstanciada na distinção desses fenômenos contemporâneos.

Tassinari (2013) adverte que a temática da judicialização da política é uma questão social que perpassa pela interação da tríade Direito, Política e Judiciário, considerando que essa dimensão social deriva originalmente de elementos alheios à jurisdição, quais sejam: amplitude do reconhecimento de direitos e ineficiência do Estado na instituição desses direitos que culminam no aumento da litigiosidade.

Entende-se, portanto, a judicialização da política como um fenômeno social, concepção também apregoada por Alexandre Veronese (2009, p. 257) como "[...] um diagnóstico de transição no relacionamento entre o Poder Judiciário e os outros dois poderes estatais". Essa expressão "diagnóstico de transição" afigura-se bastante oportuna, uma vez que a judicialização da política deve ser vista como uma visão macro (moldura social), da qual pode exsurgir (ou não) o ativismo judicial.

Assim, a judicialização da política reflete um Judiciário com excesso de litigiosidade e que possui como pressuposto primeiro a defesa da Constituição e dos direitos fundamentais, ou seja, a judicialização da política não extrapola a função típica do Judiciário, funcionando como uma espécie de rearranjo institucional como resposta à vocação expansionista do princípio democrático (SÁ; BONFIM, 2015).

Segundo Hirchl (2009 , p. 140), "[...] a judicialização da política agora inclui a transferência massiva, para os tribunais, de algumas das mais centrais e polêmicas controvérsias políticas em que uma democracia pode se envolver".

Por outro lado, o "ativismo judicial" relaciona-se à postura/atuação do Judiciário, que extrapola os limites constitucionais (TASSINARI, 2013).

Nesse contexto, o ativismo judicial (expressão carregada de valorações e complexidades práticas e teóricas), ao contrário da judicialização da política, envolve uma postura deliberada do poder judiciário (SÁ; BONFIM, 2015).

O ideal ativista vincula-se, portanto, a uma atitude mais ampla e intensa do Judiciário, com maior interferência nos espaços próprios do Executivo e do Legislativo, que, em muitas vezes, nem há substituição, mas, sim, ocupação de espaços vazios, visando à concretização dos valores e fins constitucionais; ou, mais precisamente, ao preenchimento de lacunas legislativas e lacunas de ações do executivo (CORDEIRO; CREMONEZl; NUNES JUNIOR, 2018).

Uma vez estabelecida a diferenciação e a consequente compreensão da judicialização da política e do ativismo judicial, resta o seguinte questionamento a partir do eixo central deste estudo: $\mathrm{O} \mathrm{ECl}$ decorre de alguma dessas categorias?

Tal resposta exige um aprofundamento teórico sobre o instituto do $\mathrm{ECl}$, o que será feito no item seguinte. Visando, todavia, a apenas situar o $\mathrm{ECl}$ dentre as categorias ora em análise, afirma-se, de pronto, que se trata de "[...] exemplo destacado de ativismo judicial" (CAMPOS, 2019, p. 227).

\subsection{Perspectiva Histórica}

Em continuidade ao percurso preliminar teórico, vê-se necessária a abordagem da perspectiva histórica desses institutos basilares ao presente estudo (judicialização da política e ativismo judicial). 
Seja pela via da judicialização da política ou do ativismo judicial, a origem teórica é norte-americana; então:

[...] este movimento de intensificação da atividade judiciária, que contemporaneamente se vislumbra numa perspectiva global, já foi vivenciado pelos Estados Unidos, que, em razão disso, desde a instituição do controle de constitucionalidade (judicial review) em 1803, produziu um numeroso acervo literário problematizando as atribuições, limites e competências do Poder Judiciário (TASSINARI, 2013, p. 589).

Nesse contexto, cumpre registrar a origem norte-americana na utilização da expressão ativismo judicial em 1947, em publicação jornalística na Fortune Magazine de autoria do historiador Arthur Schlesinger Jr. (TASSINARI, 2013).

Já o conceito original de judicialização foi firmado na teoria política por Tate e Vallinder (1995 apud VERONESE, 2009), cuja formulação expressa um processo político que atingiria as democracias contemporâneas em geral, sendo referido conceito amplamente absorvido na teoria social da América Latina (VERONESE, 2009).

É oportuna a análise descritiva do supracitado marco teórico conceitual, feita por Tassinari (2013, p. 582):

[...] No ano de 1995, dois cientistas políticos, Chester Neal Tate e Torbjörn Vallinder, publicaram um livro para tratar da atuação do Poder Judiciário. Contando com a participação de autores de diversas tradições, a proposta era justamente aprofundar o debate sobre o tema, problematizando o movimento das intervenções judiciais na direção do que se reconheceria por todos como exemplo americano de jurisdição. Como não poderia ser diferente, portanto, o título atribuído à obra foi: "The Global Expansion of Judicial Power" ("A Expansão Global do Poder Judiciário").

Tassinari (2013), ao abordar a questão da contemporaneidade da judicialização da política, revela que o pós Segunda Guerra Mundial trouxe um incremento na dogmática constitucional com a positivação de novos direitos, coadunada a uma nova forma de compreensão de concretização dessas garantias.

Do mesmo modo, esse protagonismo judicial, segundo Uprimny Yepes (2007), generalizou-se em muitos países, tantos os desenvolvidos quanto os do Terceiro Mundo.

Acrescentam Vieira, Lacombe e Legale (2016, p. 203) que, "[...] a partir de meados dos anos 1980, os tribunais constitucionais adquiriram um papel de protagonismo especialmente nos países do Leste Europeu, assim como em outros que vivenciaram um processo de transição democrática".

Veronese (2009), partindo também do consenso de ampliação da relevância do papel dos tribunais e de que esse papel gera tensão entre o direito e a política, revela a necessidade de compreensão do significado local atribuído aos textos constitucionais na América Latina em relação ao contexto global. Ao apreciar o quadro latino-americano, o referido autor conclui pela expansão do poder judicial nas democracias recentes como uma característica generalizada (excetuado o caso específico do Chile), com expressividade ampla justamente nos casos colombiano e brasileiro, países objeto do estudo, comparado a que se destina o presente artigo.

Arantes (2007), ao analisar as especificidades do Judiciário como instituição judicial e política, revela que as grandes transformações pelas quais passou o mundo ocidental nos séculos 18 e 19 tiveram forte impacto sobre as funções da Justiça e a organização do Judiciário. Nesse viés, destaca que a derrubada dos regimes absolutistas e a fundação dos Estados liberais na Europa e nos Estados Unidos, marcaram uma profunda transformação no papel do Judiciário.

Com efeito, das experiências constituintes paradigmáticas dos Estados Unidos da América (1787) e da França (1789) eclodiram dois modelos constitucionais distintos que influenciaram o curso histórico de diversos países (ARANTES, 2007).

Nesse contexto, sobreleva enfatizar uma espécie de premissa normativa constante nos países estudados no presente artigo: os processos constituintes vivenciados pelo Brasil (1988) e pela Colômbia (1991) não só possibilitaram, como continuam a influenciar, o ativismo judicial perpetrados tanto no Supremo Tribunal Federal (STF) quanto na Corte Constitucional da Colômbia (CCC) (VIEIRA; LACOMBE; LEGALE, 2016).

Ressalta Campos (2019) que o cenário político-institucional na América Latina, oriundo do movimento iniciado no fim dos anos 80 e início dos anos 90, de reformas constitucionais de restabelecimento ou fortalecimento da democracia (das quais decorreram constituições com extenso rol de direitos fundamentais e 
sociais), foi solo fértil para o avanço da judicialização da política e do ativismo judicial, sendo a Corte Constitucional da Colômbia (CCC) "[...] considerada paradigma do ativismo judicial na América Latina e uma das mais ativistas do mundo" (CAMPOS, 2019, p. 105).

Sobre a destacada atuação da Corte colombiana, vale ressaltar:

La Corte Constitucional colombiana es reconocida como pionera en la promoción y formulación jurisdiccional de los cánones neoconstitucionalistas en el mundo. Doctrinas como la del bloque de constitucionalidad de ese tribunal han sido verdaderamente revolucionarias, pues dejaron atrás nociones básicas del Derecho y de la teoría del Estado modernas para avanzar en las garantías del Estado Social. El ECl, sin duda, abrió una perspectiva nueva para la doctrina de la protección de los derechos fundamentales del neoconstitucionalismo a través de las acciones de amparo (PÁEZ, 2012, p. 245).

Como vanguardista do ativismo judicial, a Colômbia, por meio de sua Corte Constitucional, revelou ao mundo o mecanismo jurídico intitulado Estado de Coisas Inconstitucional (ECI), sobre o qual nos debruçaremos a seguir.

\section{ESTADO DE COISAS INCONSTITUCIONAL}

Antes de adentrarmos ao significado/conceito do $\mathrm{ECl}$, consideramos essencial a compreensão do por quê, isto é, o fundamento do surgimento dessa manifestação jurídica denominada $\mathrm{ECl}$.

Como apontado anteriormente, a América-Latina vivenciou intensos movimentos democráticos que culminaram em novos textos constitucionais com amplo catálogo de direitos fundamentais. Ocorre que os Estados falham na instituição desses direitos, seja por lacunas legislativas ou omissão do Poder Executivo. Nesse contexto, a referida omissão estatal pode ser de tal monta que implique em violação massiva e contínua de direitos fundamentais, cuja demanda é encaminhada ao Poder Judiciário que, em resposta, expede ordens estruturais aos demais Poderes para que seja superada essa realidade inconstitucional. De modo prático e sucinto, esse é o cenário do qual surge a medida jurídica extrema do $\mathrm{ECl}$.

Ainda nessa trilha de fundamentação do ECl, é necessário citar o enfoque filosófico, apontado por Campos (2019, p. 164), a partir da "[...] teoria da justiça de John Rawls, mais precisamente em sua noção de mínimo social (social minimum)":

[...] denegar quaisquer condições sociais mínimas aos mais desafortunados implica recusar-lhes a possibilidade de desenvolverem poderes morais, o que significa violar elementos constitucionais essenciais (constitucional essencial). Condições sociais mínimas são, para Rawls, indispensáveis para que os indivíduos se vejam como capazes de exercer liberdades e direitos básicos.

(...)

A proposta rawlsiana serve para justificar o papel da Corte Constitucional colombiana do mínimo existencial violado nos casos de ECI (CAMPOS, 2019, p. 164).

Superados os fundamentos, chega-se na definição. O ECl, em suma, é uma medida extrema que visa a proteger a dimensão objetiva dos direitos fundamentais ante a omissão estatal que implica violação massiva e contínua desses direitos (CAMPOS, 2019).

Como desdobramento desse conceito, Campos (2019) elenca quatro pressupostos para a declaração do $\mathrm{ECl}: 1)$ quadro de violação massiva e contínua de diferentes direitos fundamentais, que afeta um número amplo de pessoas; 2 ) omissão reiterada e persistente das autoridades públicas no cumprimento de suas obrigações de defesa e promoção dos direitos fundamentais que culminam em falhas estruturais; 3) medidas necessárias à superação das inconstitucionalidades e falhas estruturais; e, 4) potencialidade de número elevado de outros afetados ajuizarem novas demandas judiciais, o que significa tratar a questão como litígio estrutural, cujas medidas alcançam ampla população de afetados.

O ECl trata-se de construção jurisprudencial oriunda da Corte Constitucional da Colômbia, consubstanciada na Sentencia de Unificación (SU) no 559, de 6/11/1997, que versou sobre o caso relativo à omissão de dois municípios (Maria La Baja e Zambrano) em pagar direitos previdenciários e de saúde de 45 professores 
municipais. Em sede de tutela, além de reconhecer os direitos subjetivos dos professores demandantes, a CCC vislumbrou a violação dos direitos fundamentais em sua dimensão objetiva, considerando que $80 \%$ dos professores municipais encontravam-se na mesma situação (CAMPOS, 2019).

Assim, a Corte colombiana foi além (ativismo judicial) e, "[...] cumprindo o que afirmou ser um 'dever de colaboração' com os outros poderes, tomou decisão que não se limitou às partes do processo" (CAMPOS, 2019, p. 130). É o que o referido autor ressalta como "dimensão objetiva da sentença", realizada a partir de uma situação fática complexa que culmina num contexto amplo e estrutural de causas e efeitos, onde a Corte Constitucional atua para defender não um direito fundamental individual, mas o próprio sistema de direitos fundamentais, preservando não um dispositivo constitucional específico, mas, sim, a Constituição em sua totalidade (CAMPOS, 2019).

A visão de Páez (2012, p. 244) sobre o ECl também se afigura oportuna:

La doctrina del $\mathrm{ECl}$ se instituyó como una solución que adopta el juez constitucional ante la constatación de que las causas de una desprotección generalizada de derechos fundamentales obedece a causas estructurales del Estado, frente a lo cual dicta órdenes a las autoridades administrativas tendientes a dar remedio a la situación inconstitucional y que obedecerán al entendimiento que el tribunal tenga sobre las fallidas o inexistentes políticas públicas que debería aplicarse para garantizar los derechos fundamentales violados.

Como já apontado anteriormente, o ECl insere-se no já explicitado ativismo judicial. Com efeito, a declaração do $\mathrm{ECl}$ efetiva-se em meio a um cenário de falhas e bloqueios estruturais que, inevitavelmente, conduzem à conclusão de incapacidade dos demais poderes políticos de resolução da violação massiva de direitos fundamentais (CAMPOS, 2019).

Campos (2019) adere a uma proposta de categorização do ativismo judicial em cinco dimensões: dimensão metodológica, dimensão processual, dimensão estrutural ou horizontal, dimensão de direitos e dimensão antidialógica, para, então, concluir que "[...] a declaração do $\mathrm{ECl}$ e os remédios estruturais que a seguem caracterizam o ativismo judicial de dimensão predominantemente estrutural" (CAMPOS, 2019, p. 253).

Assim, o ECl correlaciona-se à figura do litígio estrutural ou processo estrutural (structural suit) caracterizado pelo alcance ampliado de pessoas (além das entidades e instituições envolvidas), bem como pela rede complexa de ordens de execução dirigidas às entidades governamentais em mau funcionamento (CAMPOS, 2019).

No contexto das demandas estruturais, é oportuno registrar sua origem estadunidense ocorrida "[...] a partir de julgamento do caso Brown vs. Board of Education of Topeka em 1954, célebre caso que decidiu sobre a segregação racial no sistema de ensino no sul dos Estados Unidos" (DANTAS, 2017, p. 156).

Já a feição contemporânea desse modelo de ativismo judicial estrutural tem sido observada "[...] em países como África do Sul, Índia, Argentina e Colômbia, onde as Cortes Constitucionais têm vislumbrado a necessidade de adoção de uma nova postura procedimental a fim de dar efetividade a direitos fundamentais de segunda dimensão" (KOZICKI; VAN DER BROOCKE, 2018, p. 158).

Visando a firmar um posicionamento a respeito do ECl, ratifica-se o posicionamento de Santos e Pereira (2016, p. 255-256), a saber:

O Estado de Coisas Inconstitucional não pressupõe a anulação da capacidade institucional dos Poderes Executivo e Legislativo; tampouco ofende o espaço legítimo de deliberação democrática. Sua própria sistemática de solução de litígios estruturais aponta para a adoção de técnicas decisórias mais flexíveis, baseadas no diálogo e na cooperação entre os diversos poderes estatais. Parte, sobretudo, de um contexto muito maior de releitura do princípio da separação dos Poderes que, no paradigma do Estado Democrático de Direito, abandona muito de seu conteúdo mais clássico e absoluto.

Doravante, adentraremos no objetivo específico do presente estudo, qual seja, a análise do $\mathrm{ECl}$ nos sistemas de justiça colombiano e brasileiro, com recorte temático relativo ao sistema prisional.

\subsection{ECl e Sistema Prisional: Colômbia e Brasil em perspectiva}

A questão carcerária é repleta de entraves e deficiências, sendo um dos grandes desafios dos governos ao redor do mundo. 
A partir de dados coletados no sítio The Word Prison Brief, um banco de dados on-line que fornece acesso gratuito a informações sobre sistemas prisionais mundiais, compilamos as seguintes informações visando à análise comparativa dos sistemas prisionais do Brasil e da Colômbia.

Tabela 1 - Sistemas Prisionais brasileiro e colombiano

\begin{tabular}{|c|c|c|}
\hline & BRASIL & COLÔMBIA \\
\hline $\begin{array}{l}\text { População prisional total (incluindo } \\
\text { detentos pré- } \\
\text { julgamento/prisioneiros de prisão) }\end{array}$ & $\begin{array}{l}755274 \\
\text { em dezembro de } 2019 \text { (administração } \\
\text { penitenciária nacional) }\end{array}$ & $\begin{array}{l}109034 \\
30.6 .2020 \text { (administração } \\
\text { penitenciária nacional) }\end{array}$ \\
\hline $\begin{array}{l}\text { Taxa populacional prisional (por } \\
100.000 \text { habitantes nacionais) }\end{array}$ & $\begin{array}{l}357 \\
\text { com base em uma população nacional } \\
\text { estimada de } 211,8 \text { milhões em } \\
\text { dezembro de } 2019 \text { (dados das Nações } \\
\text { Unidas) }\end{array}$ & $\begin{array}{l}\mathbf{2 1 7} \\
\text { com base em uma população } \\
\text { nacional estimada de } 50,22 \\
\text { milhões no final de junho de } \\
2020 \text { (dados das Nações Unidas) }\end{array}$ \\
\hline $\begin{array}{l}\text { Capacidade oficial do sistema } \\
\text { prisional }\end{array}$ & $\begin{array}{l}\mathbf{4 4 2} \mathbf{3 4 9} \\
\text { (Dezembro de 2019) }\end{array}$ & $\begin{array}{l}80928 \\
(30.6 .2020)\end{array}$ \\
\hline $\begin{array}{l}\text { Nível de ocupação (com base na } \\
\text { capacidade oficial) }\end{array}$ & $\begin{array}{l}\mathbf{1 7 0 . 7 \%} \\
\text { (Dezembro de 2019) }\end{array}$ & $\begin{array}{l}134.7 \% \\
(30.6 .2020) \\
\end{array}$ \\
\hline
\end{tabular}

Fonte: Elaborado pelas autoras com base no Word Prison Brief (ICPR, 2020).

Mesmo com o atraso de atualização dos dados entre os países ora em análise, conclui-se que a situação carcerária no Brasil é mais grave quando comparada à situação da Colômbia.

Ainda com base neste banco de dados (The Word Prison Brief) e utilizando o refinamento Highest do Lowest - Prision Population Total, verifica-se que no ranking dos 13 países da América do Sul, o Brasil e a Colômbia inserem-se no topo dessa lista como 1 e e 2 ㅇ lugares, respectivamente. No âmbito geral internacional da população prisional, o Brasil encontra-se em 30 lugar (755.274), antecedido apenas pela China (1.710.000) e pelos EUA (2.121.600), estando a Colômbia em 15o lugar nesse ranking mundial com 109.034 de total da população prisional.

Campos (2019) destaca que entre os diversos setores sociais brasileiros passíveis de violação massiva de direitos fundamentais decorrentes de falhas estruturais, o sistema carcerário talvez se enquadre como o cenário que produz o maior grau dessa violação.

A seguir, veremos o enfrentamento da questão prisional pelo Judiciário a partir do Estado de Coisas Inconstitucional.

\subsubsection{A Experiência Colombiana}

A Corte Constitucional da Colômbia (CCC) já promoveu três declarações de Estado de Coisas Inconstitucional (ECI) relativas ao sistema prisional, ${ }^{1}$ quais sejam: 1) em 1998 (Sentencia T-153/98); 2) em 2013 (Sentencia T-388/13); e 3) em 2015 (Sentencia T-762/15).

Visando à compreensão prática do $\mathrm{ECl}$, serão registradas as ideias centrais desses julgados mediante exposição de suas estruturas, e, a partir de cada item, alguns trechos descritivos ou argumentativos que se considera mais relevante:

\footnotetext{
“1. En tres oportunidades la Corte Constitucional declaró un estado de cosas inconstitucional (en adelante ECI) en materia penitenciaria y carcelaria. La primera providencia sobre la materia fue la Sentencia T-153 de 1998. Con posterioridad, esta Corporación constató avances significativos sobre las causas que sustentaron la mencionada declaratoria, de modo que estableció que la situación fue superada. Sin embargo, ante la persistencia de la violación masiva y generalizada de los derechos de las personas privadas de la libertad y la necesidad de actuaciones estatales complejas que comprometen a varias instituciones, la Sala Primera de Revisión, a través de la Sentencia T-388 de 2013, declaró nuevamente la existencia de un ECl.

El 16 de diciembre de 2015, la Sala Quinta de Revisión de la Corte profirió la Sentencia T-762 de 2015 en la que reiteró el ECI declarado en 2013, bajo la premisa de que la política criminal colombiana ha sido reactiva, populista, incoherente y subordinada a la política de seguridad, situación que ha engendrado la vulneración masiva, sistemática y generalizada de los derechos fundamentales de las personas privadas de la libertad." (COLÔMBIA, 2015).
} 
- Sentencia T-153/98

Referência: registros acumulados T-137.001 e 143.950

Atores: Manuel José Duque Arcila, Jhon Jairo Hernández e outros.

Tema: Situação inconstitucional nos centros de detenção do país

JULGAMENTO

Nos processos de tutela, números T-137001 e T-143950, promovidos por Manuel José Duque Arcila e Jhon Jairo Hernández e outros, respectivamente, contra o Ministério da Justiça e Direito e o Instituto Nacional Penitenciário e Prisional - INPEC.

\section{ANTECEDENTES}

Processo T-137001

(...)

Processo T-143950

(...)

\section{FUNDAMENTOS JURÍDICOS}

O problema jurídico

2. O objetivo é determinar se as condições em que se encontram os internos dos Presídios Nacionais Modelo de Bogotá e Bellavista em Medellín constituem uma violação dos direitos fundamentais dos internos e, em caso afirmativo, se a ação de proteção é adequada para exigir o remédio nas condições indicadas.

\section{Superlotação na Prisão Modelo Nacional em Bogotá e na Prisão do Distrito Bellavista em Medellín}

(...)

9. Pelo que foi explicado até agora, pode-se deduzir claramente que as prisões Modelo e Bellavista têm condições impressionantes de superlotação. Mas se o problema fosse reduzido a essas duas prisões, poderia-se pensar em resolvê-lo com base em alguns pedidos de transferência de presos. Infelizmente, essas duas prisões são simplesmente expoentes extraordinários de uma situação geral, como será visto abaixo.

(...)

A situação geral da superlotação das prisões no país

O fenômeno da superlotação das prisões sob uma perspectiva histórica

Lei 415 de 1997

Algumas causas explicativas da situação de congestionamento nas prisões.

Infra-estrutura prisional

Consequências da superlotação nas prisões

Direitos dos reclusos

A notória existência de uma situação inconstitucional no sistema penitenciário

(...)

51. A racionalidade constitucional é diferente da maioria. Os direitos fundamentais são precisamente uma limitação ao princípio da maioria, com o objetivo de garantir os direitos das minorias e dos indivíduos. 0 juiz constitucional é obrigado a assumir a voz de minorias esquecidas, ou seja, daqueles grupos que dificilmente têm acesso a organizações políticas. Por esse motivo, o Tribunal Constitucional é chamado a agir em ocasiões como essa, chamando a atenção para a situação inconstitucional que ocorre no sistema penitenciário colombiano e que exige a adoção de medidas pelos diferentes ramos e órgãos do poder, com o objetivo de resolver o estado de coisas que adverte reinar nas prisões colombianas.

(...)

53. Nos julgamentos SU-559 de 1997 e T-068 de 1998, esta Corporação fez uso da figura inconstitucional da situação, a fim de procurar remediar situações de violação de direitos fundamentais de caráter geral - em tanto que afetam uma multidão de pessoas - e cujas causas são de natureza estrutural - ou seja, geralmente não se originam exclusivamente da autoridade solicitada e, portanto, sua solução exige a ação conjunta de diferentes entidades. Nestas condições, o Tribunal considerou que, uma vez que milhares de pessoas estão na mesma situação e que, se todas viessem à tutela, poderiam congestionar desnecessariamente a administração da justiça, 
As prisões colombianas são caracterizadas por superlotação, sérias deficiências nos serviços públicos e de assistência social, império de violência, extorsão e corrupção e falta de oportunidades e meios para a ressocialização dos presos. A razão auxilia a Ouvidoria quando conclui que as prisões se tornaram meros repositórios de pessoas. Esta situação está totalmente de acordo com a definição do estado inconstitucional. E segue-se uma flagrante violação de uma série de direitos fundamentais dos reclusos nos centros penitenciários colombianos, como dignidade, vida e integridade pessoal, direitos à família, saúde, trabalho e presunção de inocência, etc.

\section{(...)}

65. Dada a gravidade das omissões atribuíveis a diferentes autoridades públicas, a Corte deve declarar que a situação que ocorre nas penitenciárias colombianas, descrita nesta Sentença, é inconstitucional e exige que as autoridades públicas usem imediatamente seus poderes. leis constitucionais, a fim de remediar esta situação. Para isso, procederá à emissão das respetivas ordens.

\section{DECISÃO}

(...) (COLOMBIA, 1998, grifos nosso).

- $\quad$ Sentencia T-388/13

I. ANTECEDENTES

II CONSIDERAÇÕES E FUNDAMENTOS

\section{Competência}

2. Problemas jurídicos a resolver

3. Decisões e resumo do argumento da sentença

4. A situação do sistema penitenciário encontrado em 1998 não é a mesma do que está passando atualmente, por isso requer uma análise própria e independente

5. Informações sobre a situação do sistema penitenciário e penitenciário colombiano fornecidas e compiladas pela Corte

6. Declaração do Estado de Emergência Penitenciária e Prisional

7. O sistema penitenciário e prisional está novamente em um estado de coisas contrário à Constituição Política (...)

7.2.7 Em suma, o sistema penitenciário e prisional encontra-se novamente em estado de coisas inconstitucionais porque (i) os direitos constitucionais das pessoas privadas de liberdade são violados de forma massiva e generalizada; (ii)as obrigações de respeito, proteção e garantia, derivadas de tais direitos, foram violadas há muito tempo; (iii) o Sistema institucionalizou práticas claramente inconstitucionais em suas operações diárias; (iv) há uma notável ausência de medidas legislativas, administrativas e orçamentárias urgentemente necessárias; (v) a resolução de problemas estruturais envolve a intervenção de várias entidades, que devem realizar ações complexas e coordenadas; e, por fim, (vi) se todas as pessoas privadas de liberdade que se encontram no mesmo estado de coisas apresentassem ações de proteção (ou outros mecanismos de defesa de seus direitos), como fizeram os demandantes das tutelas acumuladas nessa oportunidade.

(...)

7.4.4.5 A situação das prisões e do sistema penitenciário colombiano é indigna, mesmo pelos padrões do que normalmente era considerado o mínimo dos mínimos.

(...)

8. Toda pessoa que é privada de liberdade, ou pode ser privada de liberdade, tem o direito constitucional de ter uma política criminosa e penitenciária que respeite sua dignidade e esteja orientada a materializar o gozo efetivo de seus direitos; o estado atual da política criminal não conhece os mínimos constitucionais

(...)

\subsection{A política penitenciária está em um estado de coisas contrário à ordem constitucional atual}

(...)

8.2.2 Os problemas enfrentados pelo sistema são estruturais.

(...)

8.2.2.2 Novamente, não é apenas uma questão colombiana. Os problemas estruturais das políticas penitenciárias são um sofrimento global, como o Departamento de Planejamento Nacional apontou em um de seus documentos dedicados ao estudo da questão. A situação na Colômbia é grave, mas como afirmado, de uma 
perspectiva comparativa, não é a pior. O Planejamento Nacional descobriu que, quando a Colômbia é comparada com o que está acontecendo em outras latitudes, é evidente que a situação pode ser mais complexa do que atualmente. Isso significa que os níveis de superlotação podem continuar a aumentar e ter impactos ainda maiores na dignidade das pessoas privadas de liberdade. A crise penitenciária colombiana, portanto, é um problema sério que exige atenção urgente e eficaz.

(...)

9. Questões a serem resolvidas, comuns a todos os casos, e as específicas de cada processo e cada prisão

10. Pedidos

11. Conclusão

(...)

A Câmara considera que a situação do sistema prisional apurada em 1998 não é a mesma que está passando atualmente, pelo que necessita de sua própria análise independente. É o que demonstra a informação sobre a situação do sistema penitenciário e penitenciário colombiano, fornecida e compilada pelo Tribunal, que figura como anexo ao presente despacho, com base na qual confirma a existência de uma situação inconstitucional no sistema penitenciário colombiano.

- $\quad$ Sentencia T-762/15

Referência: expedientes acumulados:

(...)

Assunto: Violação dos direitos fundamentais das pessoas privadas de liberdade. Desarticulação da política criminal. Situação superlotada nos estabelecimentos penitenciários e prisionais do país. Reiteração do estado inconstitucional das coisas.

\section{JULGAMENTO}

\section{ANTECEDENTES}

\section{A. Processos preliminares no Tribunal Constitucional \\ B. Apresentação dos casos em estudo \\ C. Ações na sede da revisão \\ II CONSIDERAÇÕES DO TRIBUNAL CONSTITUCIONAL \\ Competência}

\section{Assunto sob revisão e problema jurídico}

2. Os demandantes exigiram a intervenção do juiz constitucional para a proteção de seus direitos fundamentais, que consideram violados em consequência das condições de confinamento a que foram submetidos em 16 estabelecimentos penitenciários. Eles solicitam medidas de intervenção basicamente destinadas a melhorar os serviços prestados e reduzir a superpopulação; as reivindicações mais regulares sobre esse último aspecto foram a imposição de restrições à entrada de prisioneiros e a transferência de alguns deles para outras prisões.

\section{Esboço da apresentação e metodologia para resolver}

Enquadramento Jurisprudencial: Julgamentos T-153 de 1998 e T-388 de 2013

\section{(...)}

10. Com efeito, o julgamento T-153 de 1998, após realizar uma análise histórica do fenômeno da ocupação prisional no país, identificado como um dos focos de ação contra a superpopulação, entre outros, a adaptação necessária da infraestrutura física do sistema penitenciário e prisional da época.

Quase 15 anos depois, a Sentença T-388 de 2013 reconheceu que os esforços na criação de uma infraestrutura prisional que expandiu a cobertura foram, em grande parte, bem-sucedidos. Por esse motivo, e ao evidenciar que, apesar dos esforços, a crise permaneceu em vigor, nesta decisão, foi dada maior ênfase à necessidade de adaptar a política criminal do país aos padrões e estruturas de proteção dos direitos das pessoas privadas de liberdade, uma vez que dessa perspectiva resultados muito mais sustentáveis podem ser alcançados.

Diferença entre o estado de coisas inconstitucional declarado por meio do julgamento T-153 de 1998 e o declarado por meio da decisão T-388 de 2013

11. Como indicado, esses julgamentos abordam um problema comum que, no entanto, possui referências temporais, factuais e estatísticas diferentes em cada um deles. Por esse motivo, a primeira análise realizada pelo acórdão T-388 de 2013 foi diferenciar o ICE declarado em 1998 do que ele próprio deu. 
Nova situação contrária à Constituição de 1991, declarada pelo julgamento T-388 de 2013, referente ao sistema penitenciário e prisional do país

$O$ estado inconstitucional das coisas. Reiteração no presente caso

PROBLEMAS ESTRUTURAIS

PRIMEIRO PROBLEMA: A desarticulação da política criminal e o estado inconstitucional das coisas

SEGUNDO PROBLEMA ESTRUTURAL: Superlotação e outras causas de violação maciça de direitos

TERCEIRO PROBLEMA ESTRUTURAL: Confinamento conjunto de pessoas acusadas e condenadas. Falta de coordenação entre as entidades territoriais e o Ministério da Justiça e Direito.

QUARTO PROBLEMA ESTRUTURAL: Sistema de saúde do setor penitenciário e penitenciário do país.

QUINTO PROBLEMA ESTRUTURAL: As condições de saúde e higiene são indignas na maioria dos estabelecimentos prisionais, e isso constitui um tratamento cruel e desumano promovido pelo Estado.

Análise dos julgamentos revisados

Ordens a adotar:

Ordens gerais

Relatórios Periódicos

Pedidos particulares

Pedidos em cada um dos casos específicos

RESOLVE

PRIMEIRO: LEVANTAR a suspensão dos termos, decretada por ordem de 20 de maio de 2015.

SEGUNDO: REITERAR a existência de um estado de coisas contrário à Constituição Política de 1991, no Sistema Penitenciário e Prisional do país, declarado pelo julgamento T-388 de 2013.

TERCEIRO: DECLARAM QUE A Política Criminal da Colômbia tem sido reativa, populista, pouco atenciosa, volátil, incoerente e subordinada à política de segurança. Da mesma forma, que o manejo histórico da Política Penal no país contribuiu para perpetuar a violação maciça dos direitos fundamentais das pessoas privadas de liberdade e atualmente impede o objetivo ressocializador da punição.

Pedidos versus casos específicos

Ordens gerais

Pedidos particulares

Disposições finais gerais (COLÔMBIA, 2015, grifos nossos).

Ao final dessa compilação, conclui-se: os julgados são extensos e exaustivos, com uma pormenorização de informações e fundamentos próprios de um instrumento igualmente complexo (ECI).

A base de argumentação dos julgados tem, sempre, os seguintes pontos principais em comum: há padrões mínimos que o Estado deve garantir a uma pessoa privada de liberdade (dignidade humana); existência de falhas de natureza estrutural no sistema penitenciário/prisional; e violação constante e sistemática dos direitos fundamentais dos detentos.

Ademais, observa-se que o julgado de 2015 (Sentencia T-762/15) é especialmente mais denso e completo que os anteriores, o que julgamos configurar exatamente a evolução e o aprimoramento do instituto jurídico (ECl) pela Corte colombiana.

\subsubsection{A experiência brasileira}

O pioneirismo da Corte colombiana em matéria de ECl logo ultrapassaria fronteiras e sistemas jurídicos, decorrência lógica do mundo globalizado no qual vivemos. Nesse contexto de entrelaçamento de sistemas jurídicos diversos, visando à resolução de questões constitucionais, em tese, coincidentes, exsurge uma necessidade dialógica.

Extrai-se importantes anotações sobre o denominado "transconstitucionalismo" de Marcelo Neves (2009 apud LOPES; FREIRE, 2016, p. 307). Vejamos: 
No âmbito dos conflitos envolvendo direitos fundamentais, o transconstitucionalismo apresenta-se especialmente útil, tendo em vista a primazia da proteção da dignidade humana. Para Neves, nesses tipos de questão, a conversação constitucional é indispensável.

\section{(...)}

Isto posto, depreende-se que, por meio do transconstitucionalismo, busca-se uma convivência pacífica fomentada a partir de "conversações" e "entrelaçamentos" entre as diferentes ordens jurídicas, dentro de um espírito de pluralidade e aceitação das diferenças que determinam a sociedade contemporânea, de modo a melhor proteger a dignidade humana.

No Brasil, o mecanismo jurídico do ECl foi recepcionado pelo Supremo Tribunal Federal quando do julgamento da medida cautelar da Arguição de Descumprimento de Preceito Fundamental no 347 (ADPF 347/ DF-MC), ocorrido em 9/9/2015, cuja decisão foi a seguinte:

Decisão: O Tribunal, apreciando os pedidos de medida cautelar formulados na inicial, por maioria e nos termos do voto do Ministro Marco Aurélio (Relator), deferiu a cautelar em relação à alínea "b", para determinar aos juízes e tribunais que, observados os artigos 9.3 do Pacto dos Direitos Civis e Políticos e 7.5 da Convenção Interamericana de Direitos Humanos, realizem, em até noventa dias, audiências de custódia, viabilizando o comparecimento do preso perante a autoridade judiciária no prazo máximo de 24 horas, contados do momento da prisão, com a ressalva do voto da Ministra Rosa Weber, que acompanhava o Relator, mas com a observância dos prazos fixados pelo CNJ, vencidos, em menor extensão, os Ministros Teori Zavascki e Roberto Barroso, que delegavam ao CNJ a regulamentação sobre o prazo da realização das audiências de custódia; em relação à alínea "h", por maioria e nos termos do voto do Relator, deferiu a cautelar para determinar à União que libere o saldo acumulado do Fundo Penitenciário Nacional para utilização com a finalidade para a qual foi criado, abstendo-se de realizar novos contingenciamentos, vencidos, em menor extensão, os Ministros Edson Fachin, Roberto Barroso e Rosa Weber, que fixavam prazo de até 60 (sessenta) dias, a contar da publicação desta decisão, para que a União procedesse à adequação para o cumprimento do que determinado; indeferiu as cautelares em relação às alíneas "a", "c" e "d", vencidos os Ministros Relator, Luiz Fux, Cármen Lúcia e o Presidente, que a deferiam; indeferiu em relação à alínea "e", vencido, em menor extensão, o Ministro Gilmar Mendes; e, por unanimidade, indeferiu a cautelar em relação à alínea " $\boldsymbol{f}$ '; em relação à alínea " $\boldsymbol{g}$ ", por maioria e nos termos do voto do Relator, o Tribunal julgou prejudicada a cautelar, vencidos os Ministros Edson Fachin, Roberto Barroso, Gilmar Mendes e Celso de Mello, que a deferiam nos termos de seus votos. O Tribunal, por maioria, deferiu a proposta do Ministro Roberto Barroso, ora reajustada, de concessão de cautelar de ofício para que se determine à União e aos Estados, e especificamente ao Estado de São Paulo, que encaminhem ao Supremo Tribunal Federal informações sobre a situação prisional, vencidos os Ministros Marco Aurélio (Relator), que reajustou seu voto, e os Ministros Luiz Fux, Cármen Lúcia e Presidente. Ausente, justificadamente, o Ministro Dias Toffoli. Presidiu o julgamento o Ministro Ricardo Lewandowski. Plenário, 09.09.2015 (BRASIL, 2015).

Do voto do relator, ministro Marco Aurélio, destacam-se os seguintes trechos que denotam as principais características da aplicação do $\mathrm{ECI}$ no ordenamento jurídico pátrio. Vejamos:

O pedido é voltado a obter do Supremo o reconhecimento de o sistema prisional brasileiro caracterizar-se como o denominado "estado de coisas inconstitucional" ante a ocorrência de violação massiva de direitos fundamentais dos presos, resultante de ações e omissões dos Poderes Públicos da União, dos Estados e do Distrito Federal, considerado o quadro de superlotação carcerária e das condições degradantes das prisões do país;

A situação vexaminosa do sistema penitenciário brasileiro: $O$ autor aponta violações sistemáticas de direitos fundamentais dos presos decorrentes do quadro revelado no sistema carcerário brasileiro. O Ministro da Justiça, José Eduardo Cardozo, comparou as prisões brasileiras às "masmorras medievais". A analogia não poderia ser melhor;

Os presídios e delegacias não oferecem, além de espaço, condições salubres mínimas. Segundo relatórios do Conselho Nacional de Justiça - CNJ, os presídios não possuem instalações adequadas à existência humana;

O quadro não é exclusivo desse ou daquele presídio. A situação mostra-se similar em todas as unidades da Federação, devendo ser reconhecida a inequívoca falência do sistema prisional brasileiro; 
A superlotação carcerária e a precariedade das instalações das delegacias e presídios, mais do que inobservância, pelo Estado, da ordem jurídica correspondente, configuram tratamento degradante, ultrajante e indigno a pessoas que se encontram sob custódia. As penas privativas de liberdade aplicadas em nossos presídios convertem-se em penas cruéis e desumanas;

A responsabilidade do Poder Público: A responsabilidade pelo estágio ao qual chegamos, como aduziu o requerente, não pode ser atribuída a um único e exclusivo Poder, mas aos três - Legislativo, Executivo e Judiciário -, e não só os da União, como também os dos estados e do Distrito Federal;

Falta coordenação institucional. O quadro inconstitucional de violação generalizada e contínua dos direitos fundamentais dos presos é diariamente agravado em razão de ações e omissões, falhas estruturais, de todos os poderes públicos da União, dos estados e do Distrito Federal, sobressaindo a sistemática inércia e incapacidade das autoridades públicas em superá-lo;

A ausência de medidas legislativas, administrativas e orçamentárias eficazes representa falha estrutural a gerar tanto a violação sistemática dos direitos, quanto a perpetuação e o agravamento da situação. A inércia, como dito, não é de uma única autoridade pública - do Legislativo ou do Executivo de uma particular unidade federativa -, e sim do funcionamento deficiente do Estado como um todo;

A responsabilidade do Poder Público é sistêmica, revelado amplo espectro de deficiência nas ações estatais. Tem-se a denominada "falha estatal estrutural";

Ante tal quadro, a solução, ou conjunto de soluções, para ganhar efetividade, deve possuir alcance orgânico de mesma extensão, ou seja, deve envolver a atuação coordenada e mutuamente complementar do Legislativo, do Executivo e do Judiciário, dos diferentes níveis federativos, e não apenas de um único órgão ou entidade;

Trata-se do que a doutrina vem designando de "litígio estrutural", no qual são necessárias outras políticas públicas ou correção daquelas que não alcançam os objetivos desejados, alocação de recursos orçamentários, ajustes nos arranjos institucionais e nas próprias instituições, novas interpretações e aplicações das leis penais, enfim, um amplo conjunto de mudanças estruturais, envolvida uma pluralidade de autoridades públicas;

O possível papel do Supremo: O requerente diz estar configurado o denominado, pela Corte Constitucional da Colômbia, de "estado de coisas inconstitucional". Segundo as decisões desse Tribunal, há três pressupostos principais: situação de violação generalizada de direitos fundamentais; inércia ou incapacidade reiterada e persistente das autoridades públicas em modificar a situação; a superação das transgressões exigir a atuação não apenas de um órgão, e sim de uma pluralidade de autoridades (Corte Constitucional da Colômbia, Sentencia no SU-559, de 6 de novembro de 1997; Sentencia T-068, de 5 de março de 1998; Sentencia SU - 250, de 26 de maio de 1998; Sentencia T-590, de 20 de outubro de 1998; Sentencia T- 525, de 23 de julho de 1999 ; Sentencia T-153, de 28 de abril de 1998; Sentencia T-025, de 22 de janeiro de 2004);

As dificuldades em se definir o alcance maior do termo não impedem, tendo em conta o quadro relatado, seja consignada uma zona de certeza positiva: o sistema carcerário brasileiro enquadra-se na denominação de "estado de coisas inconstitucional"

A forte violação de direitos fundamentais, alcançando a transgressão à dignidade da pessoa humana e ao próprio mínimo existencial justifica a atuação mais assertiva do Tribunal;

Esse é, enfim, o papel que deve desempenhar o Tribunal em favor da superação do quadro de inconstitucionalidades do sistema prisional: retirar as autoridades públicas do estado de letargia, provocar a formulação de novas políticas públicas, aumentar a deliberação política e social sobre a matéria e monitorar o sucesso da implementação das providências escolhidas, assegurando, assim, a efetividade prática das soluções propostas. Ordens flexíveis sob monitoramento previnem a supremacia judicial e, ao mesmo tempo, promovem a integração institucional cogitada pelo ministro Gilmar Mendes, formuladas que são no marco de um constitucionalismo cooperativo (BRASIL, 2015).

É oportuno registrar a movimentação processual datada de 5/9/2019, que aponta manifestação da Procuradoria-Geral da República. Desse parecer da PGR, extrai-se o seguinte trecho, bastante apropriado para trazer a reflexão de que a experiência brasileira, ora narrada, ainda persiste. Vejamos:

Constatado o desrespeito ao mínimo essencial de direitos fundamentais da população carcerária em decorrência de falhas estruturais em políticas públicas, não há espaço para análise de possibilidades orçamentárias. Cabe aos órgãos estatais garantir a eficácia mínima dos direitos fundamentais, em respeito à força normativa da Constituição e ao princípio da dignidade da pessoa humana. Nesse contexto, não há discricionariedade dos Poderes da União, dos Estados e do Distrito Federal, de forma que, na ausência de observância das garantias fundamentais, deve o Judiciário e, sobretudo, o Supremo Tribunal Federal, garantir o respeito à Constituição 
do Brasil. Merecem acolhida, portanto, os pedidos de determinação à União, aos Estados e ao Distrito Federal de elaboração de planos de ação voltados a racionalizar o sistema prisional e superar o estado de coisas inconstitucional que o assola, nos termos postulados nas alíneas "c" e seguintes da petição inicial (BRASIL, 2019, p. 34).

A assertiva supra demonstra a necessidade de se observar o cumprimento do mínimo existencial da pessoa humana contrapondo ao argumento da reserva do possível ou de limitações orçamentárias do Estado. Neste sentido, deve-se buscar, com inspiração em Bobbio (2004), que os direitos fundamentais sejam um compromisso com a justiça social, abrangendo a questão da distribuição de renda e o enfrentamento às desigualdades econômicas e sociais. Os direitos fundamentais devem incluir como proteção fundamental os grupos vulneráveis, ou seja, as necessidades fundamentais não podem estar condicionadas à caridade, ao resíduo, ao que sobra ou ao que é possível, mas estruturadas em políticas públicas que consolidem e garantam a concretização dos direitos insculpidos na Constituição Federal de 1988.

\section{CONSIDERAÇÕES FINAIS}

O presente artigo trouxe algumas reflexões sobre o Estado de Coisas Inconstitucional na perspectiva comparada de aplicação na Colômbia e no Brasil sobre o objeto da política penitenciária.

A partir do estudo realizado, percebeu-se a complexidade da temática principal (ECI), seja porque adentra em assuntos densos, como judicialização da política e ativismo judicial, ou pelo fato de tratar das chamadas demandas estruturais que envolvem a tão delicada violação massiva de direitos fundamentais e o reconhecimento da deficiência/inércia do aparato estatal quanto à instituição de políticas públicas.

Com efeito, o estudo comparativo da jurisdição constitucional de realidades socioeconômicas (latino-americanas) que se assemelham, trouxe também a coincidência da necessidade de enfrentamento das mazelas que assolam o sistema prisional dos países estudados, e que, inclusive, ainda se encontram presentes no contexto atual, sendo o caso carcerário brasileiro ainda mais alarmante.

Do mesmo modo, sobreleva ressaltar a importância que reside no presente estudo, considerando que o caso brasileiro da aplicação do $\mathrm{ECl}$ fora decidido apenas em sede de medida cautelar. Assim, a expertise colombiana, seja pelo pioneirismo na criação do ECl ou por sua tripla utilização em matéria prisional, narrada no presente artigo, certamente contribui para o aprimoramento do instituto, para o Brasil ou para qualquer outro ordenamento jurídico internacional.

Como se vê, a necessidade de aprofundamento do tema deste artigo é evidente, sendo o presente estudo apenas uma pequena semente lançada no terreno tão fértil da dogmática constitucional contemporânea.

\section{REFERÊNCIAS}

ARANTES, Rogério Bastos. Judiciário: entre a justiça e a política. In: AVELAR, Lucia; CINTRA, Antonio Octavio (org.). Sistema político brasileiro: uma introdução. Rio de Janeiro: F. Konrad Adenauer; São Paulo: Edunesp, 2007. p. 81-115.

BOBBIO, Norberto. A era dos direitos. Tradução Carlos Nelson Coutinho. Rio de Janeiro: Elsevier, 2004.

HIRSCHL, Ran. O novo constitucionalismo e a judicialização da política pura no mundo. Revista de Direito Administrativo, Rio de Janeiro, v. 251, p. 139-178, maio 2009. Disponível em: http://bibliotecadigital.fgv.br/ojs/index.php/rda/article/ view/7533/6027. Acesso em: 11 jul. 2020.

BRASIL. Supremo Tribunal Federal. ADPF 347/DF-MC. 2015. Disponível em: http://portal.stf.jus.br/processos/detalhe.asp?incidente=4783560. Acesso em: 9 dez. 2019.

BRASIL. Ministério Público Federal. Arguição de descumprimento de preceito fundamental 347/DF. № 325/2019 - SFCONST/ PGR. Disponível em: http://portal.stf.jus.br/processos/downloadPeca.asp?id=15341040733\&ext=.pdf. Acesso em: 9 dez. 2019.

CAMPOS, Carlos Alexandre de Azevedo. Estado de coisas inconstitucional. Salvador: JusPodivm, 2019.

COLÔMBIA. Corte Constitucional da Colômbia. Sentencia SU.559/97. Disponível em: https://www.corteconstitucional.gov.co/ relatoria/1997/SU559-97.htm. Acesso em: 10 dez. 2019.

COLÔMBIA. Corte Constitucional da Colômbia. Sentencia T-153/98. Disponível em: https://www.corteconstitucional.gov.co/ Relatoria/1998/T-153-98.htm Acesso em: 12 dez. 2019.

COLÔMBIA. Corte Constitucional da Colômbia. Sentencia T-388/13. Disponível em: https://www.corteconstitucional.gov.co/ Relatoria/2013/T-388-13.htm Acesso em: 12 dez. 2019. 
COLÔMBIA. Corte Constitucional da Colômbia. Sentencia T-762/15. Disponível em https://www.corteconstitucional.gov.co/Relatoria/2015/T-762-15.htm Acesso em: 12 dez. 2019.

CORDEIRO, Fabiana Aparecida Menegazzo; CREMONEZI, Heloisa; NUNES JUNIOR, Vidal Serrano. O ativismo judicial do Supremo Tribunal Federal Brasileiro (STF) instrumentalizado pela Súmula Vinculante, pela Ação de Descumprimento de Preceito Fundamental (ADPF) e pelo silêncio. Revista da Faculdade de Direito, Porto Alegre, RS, n. 38, ago. 2018. Disponível em: https:// seer.ufrgs.br/revfacdir/article/view/73421. Acesso em: 11 jul. 2020.

DANTAS, Eduardo Sousa. Ações estruturais, direitos fundamentais e o estado de coisas inconstitucional. Revista Digital Constituição e Garantia de Direitos, v. 9, n. 2, p. 155-176, 8 jun. 2017. Disponível em: https://periodicos.ufrn.br/constituicaoegarantiadedireitos/article/view/12258. Acesso em: 11 jul. 2020.

ICPR. Instituto de Pesquisa de Políticas de Crime e Justiça (ICPR). Institute for Crime \& Justice Policy Research/Word Prison Brief. Disponível em: https://www.icpr.org.uk https://www.prisonstudies.org/. Acesso em: 11 jul. 2020.

KOZICKI, Katya; VAN DER BROOCKE, Bianca Maruszczak Schneider. A ADPF 347 e o "Estado de Coisas Inconstitucional": ativismo dialógico e democratização do controle de constitucionalidade no Brasil. Direito, Estado e Sociedade, n. 53, p. 147-181 jul./ dez. 2018. Disponível em: http://direitoestadosociedade.jur.puc-rio.br/media/art\%206\%20direito\%2053.pdf. Acesso em: 11 jul. 2020.

LOPES, Ana Maria D’Ávila; FREIRE, Cylviane Maria Cavalcante de Brito Pinheiro. O reconhecimento do estado de coisas inconstitucional no sistema penitenciário brasileiro: análise da decisão judicial da MCADPF no 347 a partir da teoria do transconstitucionalismo. Direitos Fundamentais \& Justiça, Belo Horizonte, ano 10, n. 35, p. 285-312, jul./dez. 2016. Disponível em: http:// dfj.emnuvens.com.br/dfj/article/view/103. Acesso em: 11 jul. 2020.

MARCONI, Marina de Andrade; LAKATOS, Eva Maria. Metodologia científica. 5. ed. Rio de Janeiro: Atlas, 2007.

PÁEZ, Nicolás Augusto Romero. La doctrina del estado de cosas inconstitucional em Colombia: novidades del neoconstitucionalismo y "la inconstitucionalidade de la realidade". Revista Derecho Público Iberoamericano, n. 1, p. 243-264, 2012. Disponível em: https://dialnet.unirioja.es/ejemplar/438068 Acesso em: 12 jul. 2020.

SÁ, Mariana Oliveira de; BONFIM, Vinícius Silva. A atuação do Supremo Tribunal Federal frente aos fenômenos da judicialização da política e do ativismo judicial. Revista Brasileira de Políticas Públicas, Brasília, v. 5, n. Especial, p. 169-189, 2015.

SANTOS, Gabriel Faustino; PEREIRA, Camilla Martins Mendes. Em busca de alternativas para a judicialização da saúde: o estado de coisas inconstitucional na saúde pública brasileira. Revista de Direito Sociais e Políticas Públicas, Brasília, v. 2, n. 1, p. 67-84, jan./jun. 2016.

TASSINARI, Clarissa. Jurisdição e ativismo judicial: limites de atuação do judiciário. Porto Alegre: Livraria do Advogado Editora, 2013.

UPRIMNY YEPES, Rodrigo. A judicialização da política na Colômbia: casos, potencialidades e riscos. Revista Internacional de Direitos Humanos, São Paulo, v. 4, n. 6, p. 52-69, 2007.

VERONESE, Alexandre. A judicialização da política na América Latina: panorama do debate teórico contemporâneo. Escritos (Fundação Casa de Rui Barbosa), v. 3, 2009.

VIEIRA, José Ribas; LACOMBE, Margarida; LEGALE, Siddharta (coord.). Jurisdição constitucional e direito constitucional internacional. Belo Horizonte: Fórum, 2016. 250 p. E-book. 